\title{
Systematic Literature Review on Application of Blockchain Technology in E-Finance and Financial Services
}

\author{
Sonal Trivedi ${ }^{1}$, Kiran Mehta ${ }^{1}$, Renuka Sharma ${ }^{1}$
}

\begin{abstract}
Blockchain is thought to be the most recent innovation in technology. Trust is especially important in areas like the banking sector. Blockchain technology is a decentralised, coded security system which permits the development of novel digital platforms and services using this developing technology. The current research focuses on the usage of blockchain technology in the financial and e-finance sectors. The study focuses of research questions such as the development of blockchain technology, the adoption \& challenges in blockchain technology and the application of blockchain technology in the financial sector. This study conducted a systematic review of 76 scientific articles on blockchain technology, narrowing down the selection to 59 articles. As a result, the author created classification framework with three dimensions: blockchain development, challenges and applications in the financial sector. This study recognizes consequences for blockchain research and practice in the future. The study reveals that blockchain has various unexplored application in finance sector and also there is a scope of improvement in technology. Also, the technology is unregulated, thus, it is still in its nascent stage and a lot is to be done in the field.
\end{abstract}

Keywords: Blockchain technology; e-Finance; Financial Sector; Cryptocurrency; bitcoin; Systematic Literature Review

Submitted: August $3^{\text {rd }}, 2021 /$ Approved: October $26^{\text {th }}, 2021$

\section{Introduction}

The present study focuses on application or usage of blockchain in efinance and financial services. The study was conducted by systematic literature review of previous studies beyond 2017 and for analyzing the content, thematic analysis was conducted. In contrast to previous studies, this study not only focuses on use of blockchain technology in e-finance but also questions whether the present financial system supports blockchain technology. The study in first presents the overview of e-finance, financial service industry and blockchain technology and then addresses the research problem.

\section{E-finance and financial services industry}

E-finance is delivering customers financial services through an electronic medium, such as the internet (Allen, McAndrews \& Strahan, 2002). To put it another way, e-finance is using ICT (information and communication technology) for providing financial services to consumers. ICT is increasingly being used in the financial sector since it saves time, paper, and is a secure way of providing services (Asongu \& Nnanna, 2018). Following the rise of e-commerce in every sector, e-finance has gained prominence (Shahrokhi, 2008). Customers' increased usage of the internet, mobile phones, and laptops has prompted the financial sector to offer ICT-based services. As a result, e-finance represents a shift in the financial sector from the physical to the virtual world. E-finance is electronic delivery of financial assets to clients and enterprises through the internet (Claessens, Glaessner \& Klingebiel, 2002). As a result, all forms of financial services, including stock trading, insurance, banking, and so on, are available in an electronic format over the internet. E-finance, according to UNCTAD, is delivery of financial services through the internet (Hadidi, 2003). Efinance includes e-insurance, e-banking, and online broking, among other things. ICT is used in all aspects of the financial sector, including the back and front offices, transactions, information sharing, and so on.

Financial service sector has changed in past decade drastically in terms of applying IT technology in its processes and operations (Kong \& Loubere, 2021). Most of the financial organizations has by now understand the importance of IT department and they have found technologies game changer for business both in terms of cost cutting and increasing efficiency (Hendrikse Van Meeteren \& Bassens, 2020). There are various start-ups in the field of FinTech in past decade. Also, customer satisfactions and demand has also increased with better services in the sector of finance.

\section{Blockchain and its impact}

Blockchain technology is kind of a decentralised DLT (Distributed Ledger Technology). It's a "chain of blocks" where every block carries a hash as well as timestamped digital data, which is a unique identifier. Since its inception, the use of blockchain in financial services has been seen as the technology's principal application case. The concept gained a lot of attention when it was used for the cryptocurrency Bitcoin in 2009. Blockchain's distinct properties have the ability to significantly aid the finance industry.

Blockchain technology in finance sector. Blockchain in finance refers to applying blockchain technology in various functions and operations related to financial services industry.

(1) Chitkara Business School, Chitkara University, Punjab, India

${ }^{*}$ Corresponding author: sonal.trivedi@chitkara.edu.in 
Financial services can benefit from development of blockchain technology in varied ways. The usage of blockchain in financial services has resulted in the emergence of decentralised finance, also known as DeFi.

Bitcoin (Silva \& Junior, 2016) can be referred to as introduction of blockchain technology to world, and it was first restricted to usage as a method of cryptography for propagating bitcoin \& related transactions by cryptocurrency (Naughton, 2016; Islam et al., 2019a, 2019b). However, in last 5 years, blockchain has increased in popularity in a variety of industries, including supply chain management and IoT (Novo, 2018; Reyna et al., 2018; Jaoude \& Saade, 2019).

In addition, according to Statista (2020), in current years the market of blockchain has grown quickly globally and it is expected to grow further by 2025 to a business amounting 39 billion dollars. The reason behind this exponential growth of blockchain is its features such as trust, transparency, digital transaction, platform for multistakeholder etc. (Yli-Huumo et al., 2016; Iansiti and Lakhani, 2017; Böhme et al., 2015). Researchers consider blockchain as foundation technology (Iansiti and Lakhani, 2017). Thus, various studies have been conducted to discover the usage of blockchain technology. The current study focuses on how useful is blockchain technology in the field of e-finance and financial industry.Applying blockchain technology in e-finance. E-finance includes e-insurance, e-banking, and online broking, among other things. Despite the fact that E-banking allows consumers to access a wide range of services anywhere and anytime. The majority of research studies have indicated that security is the most significant barrier to adoption. Because the digital world is full of known and unknown cyber threats, critical data must be protected immediately. Blockchain is a relatively new technology that merely intervenes to address issues. It is essentially a linked list of blocks (public ledgers) that uses hash algorithms and timestamps to store data anonymously with other participants in the chain. It reduces traditional banking's reliance on third parties, minimising the danger of central point vulnerability. Data alteration is impossible due to the use of a one-way hash technique. There is no need to design a distributed trust architecture because all transactional data is vetted with all key stakeholders.

Smart contracts are contracts which are self-executing with terms and conditions mentioned on a blockchain. The link between blockchain and smart contracts are recently being considered by various organizations. A person may, for example, create a smart contract to encode his or her will as a set of rules on the blockchain. If the testator dies, smart contract can transfer automatically any asset including the testator's money to the beneficiary. The testator can place further limits on the beneficiary, such as permitting him or her to transfer only when they attain the age of majority, get a diploma, and so on. With sufficient investments from enterprises, the insurance industry, like many others, began studying blockchain technology application. In insurance industry, blockchain could improve a range of internal operations (from fraud detection to consumer acquisition, for example) and even help companies expand into new areas.
Figure 1: Application of Blockchain technology in financial services

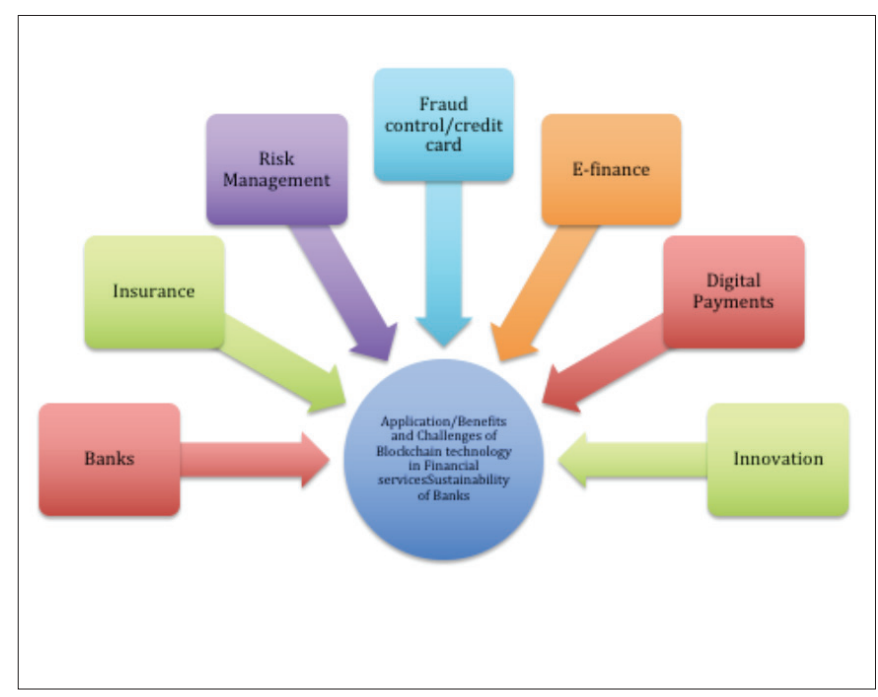

Source: Authors' compilation

Figure 1 provides an overview of the scope where blockchain technology can implemented in financial service industry and e-finance. The next section explains the research methodology used to conduct the research and further, study conducts systematic literature review to identify gap between the scope of blockchain in financial industry and the studies already conducted in the field.

\section{Research Methodology}

This current study is intended to perform a systematic review of literature related to blockchain technology usage transversely among different industries in general and more specifically in context to the finance sector. Therefore, the research methodology broadly covers the following aspects.

It is widely known that systematic reviews are applied in studies to solve queries related to a subject. Systematic reviews are extra comprehensive and distinct method of analyzing the literature in a given discipline (Cronin, Ryan, \& Coughlan, 2008), therefore we adopted an SLR strategy to achieve our research goals. An SLR technique demands specifying the time range for studies to be included, as well as the process for analysing and synthesising study results. To ensure the review's reliability and validity, it's crucial to address the following criteria before beginning SLR (Parahoo, 2006).

Frame research question.

- Establish criteria for inclusion and exclusion.

- Choose and read the literature.

- Examine the eminence of the sources used for review.

- Analyze, synthesise, \& communicate learning.

In the current study, the above-mentioned steps were followed as under. 
Figure 2: Steps in conducting SLR

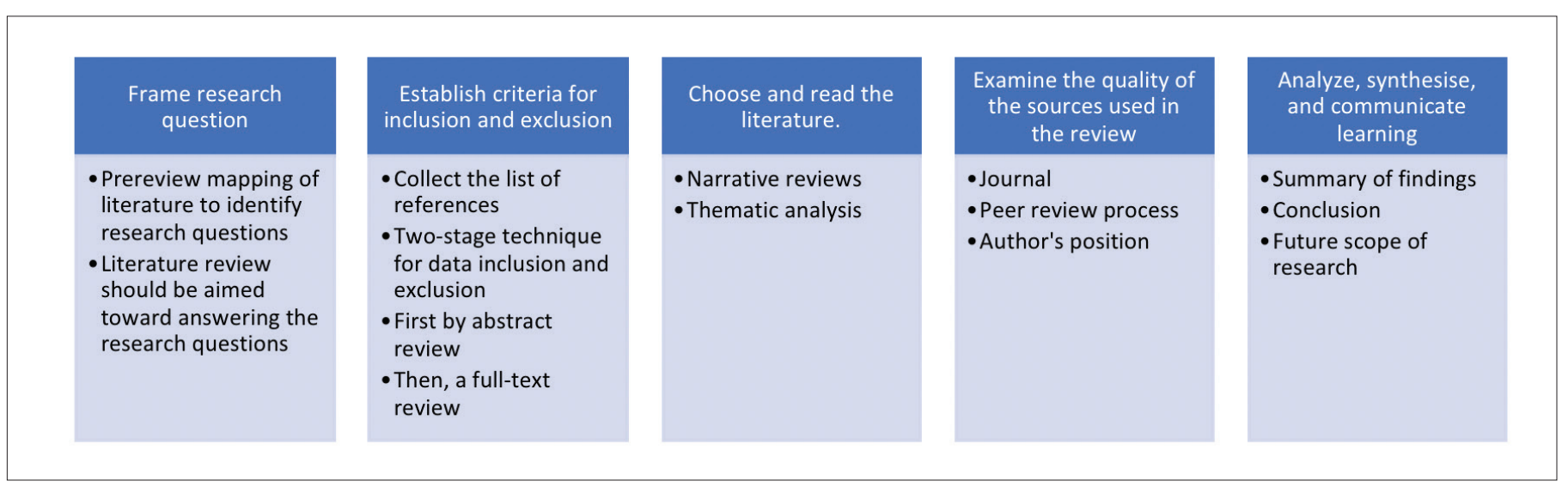

Source: Authors' compilation

\section{Frame research questions}

The next phase in an SLR-based research study is to build research questions. Research questions should guide all types of inquiries. As a result, research questions should guide thematic literature reviews. Other decisions on paper inclusion, synthesis technique \& data extraction, and making report with the goal of addressing the research questions in consideration (Levy and Ellis, 2006; Kitchenham et al. 2009).

It takes a long time to develop clear and justifiable research questions (Breretona et al., 2007).

Preview mapping can be used by researchers to find subtopics within a given study subject. The current study used a rapid mapping technique to develop research questions after conducting an initial literature search. The statements of research questions addressed in the next sections are listed below.

Problem statement. Blockchain is a novel and progressive technology that is moving numerous businesses further. Now, Blockchain is also popular for financial transactions, and it is helping various banks and financial organizations protect their everyday financial activities. Numerous research have been conducted on the use of blockchain in various industries.

There are various studies beyond 2017 based on systematic literature review of blockchain technology (Ali et al. 2020; Casino, Dasaklis \& Patsakis, 2018; Kumar \& Navin, 2021; Klarin, 2020; Vranken, 2017; Kimani et al. 2020; Hassani, Huang and Silva, 2018; Janssen et al. 2020; Merediz-Solà \& Bariviera, 2019; Nawari \& Ravindran, 2019; Taylor et al. 2019; Ante, 2020; Yang, 2019)

The current research focuses on the usage of blockchain technology in the financial and e-finance sectors.

Research question. The following research issues are addressed in the current study based on primary literature review of above mentioned research papers.
RQ1 - How the blockchain technology was developed?

RQ2 - What are the adoption and challenges in blockchain technology?

RQ3- What is the application of blockchain technology in the financial sector?

\section{Establish criteria for inclusion and exclusion}

At first the articles were extracted from one of the most popular online databases, i.e., 'Science Direct'. Initially, the papers were included based on keywords, title and abstract. After that, a careful scrutiny was done of references cited in relevant papers. Therefore, a few studies selected from the reference list of useful literature were also included in SLR. We have taken due care that only papers published in well acknowledged journals and databases are included in the final list of papers.

\section{Choose and read the literature}

"Narrative reviews" are the most frequent method for producing an initial combination of findings across all of the publications involved (Kastner et al. 2012). The current study conducted thematic analysis to identify the themes for SLR. Identifying strong or recurrent themes in the literature (which are determined by study questions) and consolidating the findings of multiple studies into thematic categories is core of thematic analysis (Mays, 2005).

\section{Examine the quality of the sources used in the review}

The selection of journals, peer review process, authors' position determine the quality and credibility of source of information (Hek and Langton, 2000). The study's quality and reliability were maintained by eliminating grey literature such as conference proceedings and working papers. Furthermore, content is evaluated for its accuracy and consistency with existing knowledge on the subject.

\section{Analyze, synthesise, and communicate learning}

At the end, the current study has summarized the findings obtained under various themes and sub-themes. The gaps thus identified will 


\section{Literature Review}

justify the objectives of the study. A concise description of the findings based on current knowledge and provides a case for pursuing future research should be included at the end of the review (Cronin, Ryan and Coughlan, 2008).
The research classification framework was developed with the help of a literature review (refer table 1 in Annexure). The dimensions and categories of the classification framework is explained below in the following sections-

Figure 3: Research framework

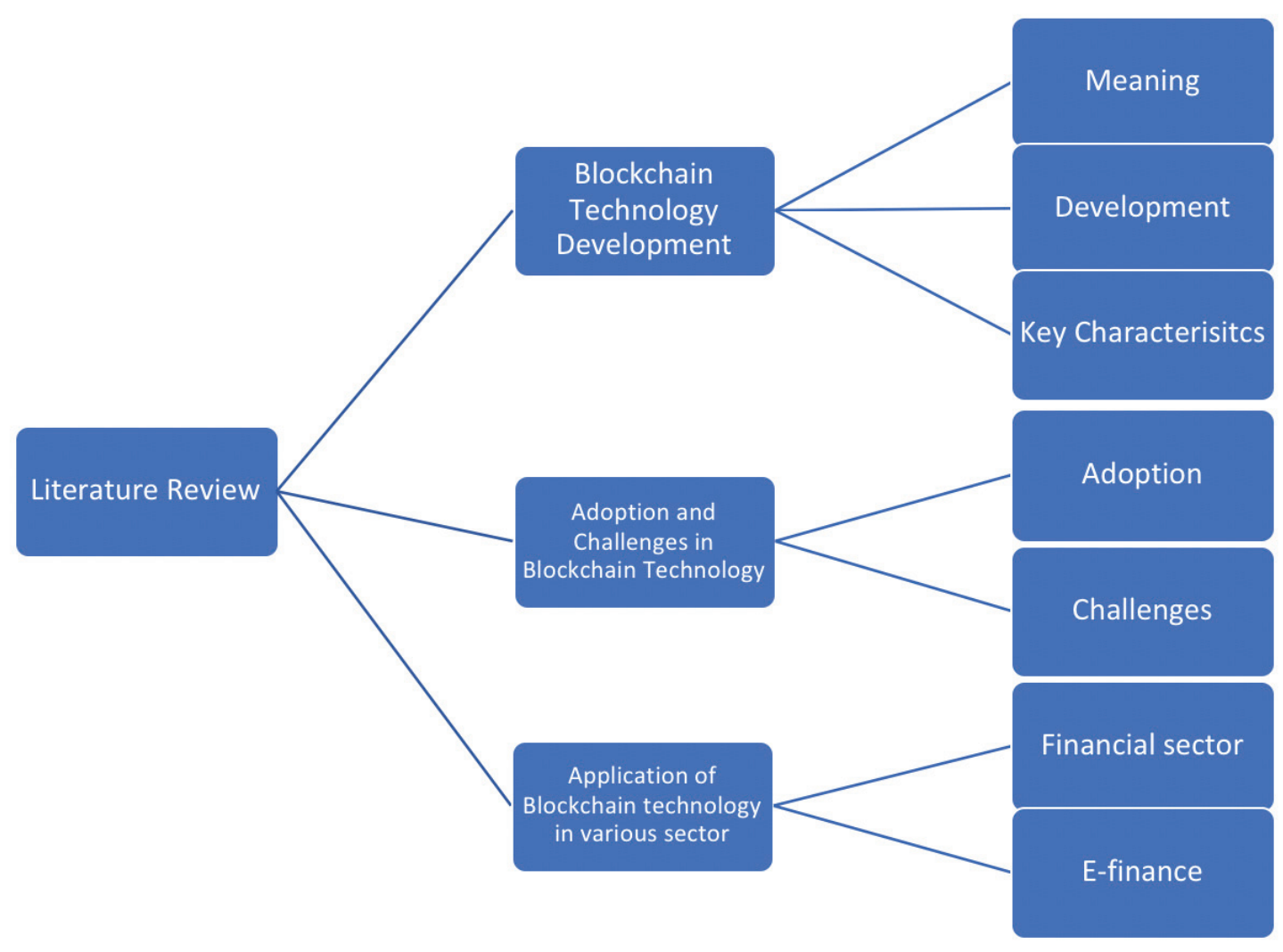

Source: Authors' compilation

Before explaining the usgae of blockchain technology in e-finance and financial sector, the development of blockchain technology and challenges faced in application of blockchain in various industries majorly related to finance is explained. The next section presents the development of blockchain technology.

\section{Blockchain technology development}

Meaning of Blockchain technology The blockchain is a decentralised ledger which accounts transactions on multiple computers at the same time (Abramova \& Böhme, 2016). Satoshi Nakamoto, a pseudonym, created the first blockchain and defined and implemented it (The Economist, 2015).

Also, a blockchain is a P2P (peer-to-peer) distributed database which is network-based concept. It comprises a series of blocks containing transactions which are time-stamped and verified by the network community and protected by PKI (public-key infrastructure). An element of blockchain cannot be modified after it has been added to the blockchain. Also, it keeps a permanent account of earlier actions (Zachariadis, Hileman \& Scott, 2019).

Furthermore, Blockchain is projected to kickstart the industrial and commercial revolution while also promoting global economic reform. To begin, Blockchain creates a security code in digital form using encryption. Users can then confirm the purchase without having to give any individual data. The transaction will be completed automatically and dispersed since the Blockchain record is unchangeable (Chang et al. 2020).

Additionally, Blockchain is also termed as the "next-generation Internet," "a new foundational technology" by the ability to restructure financial transactions, impact in what way individuals interrelate in the economy, and bring change in economy (Zachariadisa, Hilemanb \& 
Scottc, 2019). Also, Blockchain is a secure database and decentralised system of transactions that is powered by decentralised nodes (Ertz \& Boily, 2019). In other words, Blockchain is a game-changing technology that has attracted the attention of corporations and governments globally. Essentially, the term "distributed ledger technology" denotes to a collection of transactions and data which are sequentially traced \& registered over a network of distributed ledgers. (Rashideh, 2020).

Also, Blockchain is the cryptocurrency's backbone technology, which may be thought of as an append-only register where transactions are recorded (Zhong et al. 2019). The blockchain system's whole data is publicly accessible, and it is reviewed for steadiness by a group of decentralised nodes that maintain the system.

Blockchain is also demarcated as a continuously expanding record list, referred to as blocks, that are connected together using encryption (Lin et al. 2020). Blockchains are used as transaction ledgers in cryptocurrency systems like Bitcoin and Ethereum, where the blockchain keeps track of the current state and previous transactions. Blockchain can be additionally defined as a collection of blocks which stock data in hash functions and include a link to the previous block \& timestamp (Janssen et al. 2020).

Blockchain is a distributed database that only allows new data to be appended to existing data (Nijeholt, Oudejans and Erkin, 2017). It is made up of blocks, each of which carries a list of transactions and a hash pointer to the block before it, making a chain. As a result, adding a block to the chain's end is the sole option. A consensus procedure determines the content of a new block that will be attached.

Figure 4: Terms defining Blockchain

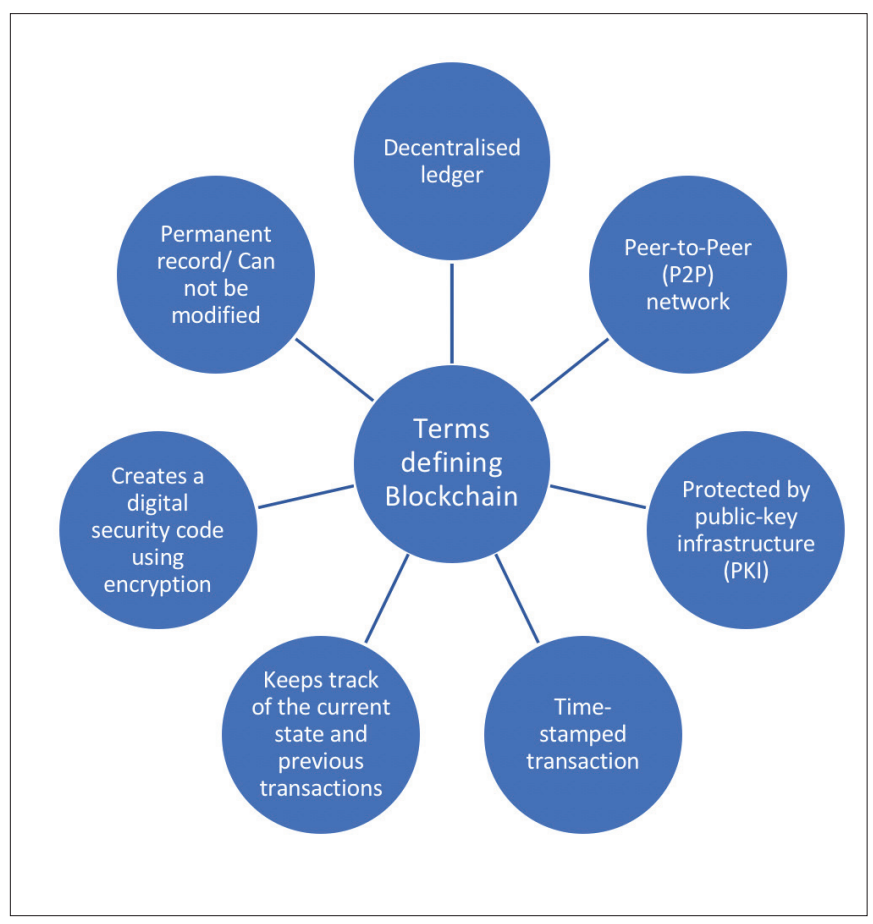

Source: Authors' compilation
Based on the foregoing definitions, a blockchain can be defined as a database model which is distributed \& based on a P-2-P network which comprises a series of blocks containing transactions that are time-stamped, verified by the network community, cannot be modified once it has been added and protected by PKI (public-key infrastructure)

The next section explains how blockchain was developed.

Development of Blockchain technology. The evolution of blockchain can be explained in 3 stages viz. - Blockchain 1.0, Blockchain 2.0 and Blockchain 3.0 (Chang et al. 2020; Kar and Navin, 2021). This section provides the explanation of these three stages or generation of blockchain technology development based on above mentioned papers.

Blockchain technology has progressed through three technological generations: Generation \#1 as currency such as Bitcoin. Apart from bitcoin, the most prominent cryptocurrency, around 600 others have been established and are utilised as exchange tokens in bitcoin-based apps. Ethereum, Monero, and Ripple are the other most popular ones (Kar \& Navin, 2020).

Generation \#2 as not only monetary transactions, but also covers bonds, smart contracts, futures, loans and mortgages. The integration of smart contracts with blockchain is the most crucial characteristic of this stage. When certain criteria are met, smart contracts are sections of code buried in it which react in a specific way (Kar \& Navin, 2020). Smart contracts can be utilised for a diversity of purposes.

Generation \#3 as a universal platform or application used by Government, research, medicine, culture, art, and literacy. The government can use blockchain to promote citizen transparency in its operations (Kar \& Navin, 2020). They could, for example, save the votes on a blockchain network and make them more visible to the public.

Figure 5: Development of Blockchain

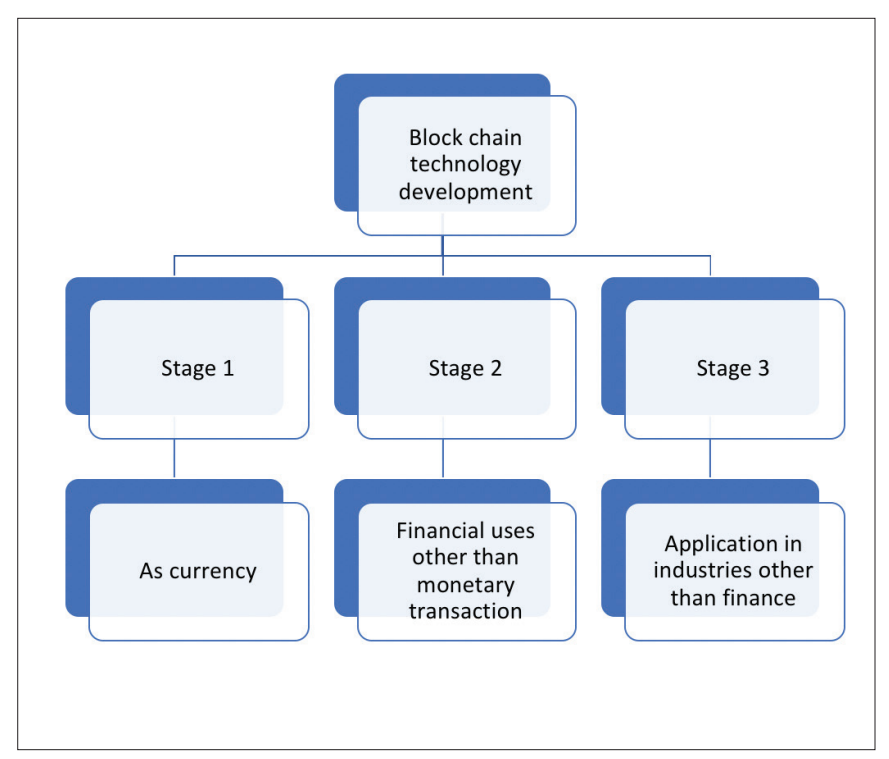

Source: Authors' compilation 
Thus, the first use of blockchain was in encryption and decentralised networks. After that, in 2013, the Ethereum project was created by developing a blockchain structure in Turing's entire language which allows operators to develop contracts to execute any function and automate commercial activities (Vitalik Buterin, 2014). Other applications of blockchain include trading platform named Linq which is based on block trading technology that was launched in 2015, marking a significant landmark in the global securities market's decentralisation trend; in 2016, Distributed Ledger Technology promoted the use of blockchain in government and financial affairs in the United Kingdom. In addition, the People's Bank of China hosted a digital money symposium to discover the idea to use blockchain for releasing virtual money for improving convenience, transparency and competence of financial transactions. Blockchain technologies have the potential to eliminate financial exclusion by overcoming the obstacles of high costs, financial illiteracy, geographical access and inadequate banking products (Schuetz and Venkatesh, 2019).

Thus, this section gives a synopsis of development of blockchain in different sectors/industries. The next section presents the key features of blockchain.

Key characteristics of blockchain technology. The characteristics of blockchain are trust and decentralization (Ali et al. 2020); user's anonymity, decentralization, execution \& consensus mechanism (Chang et al. 2020). The explanation of these terms is given below-

Trust - The blockchain's distinguishing feature is its decentralised method. The network is protected by the proof-of-work protocol, which removes the need to entrust any intermediary to record \& verify transactions, thus operators do not require to rely on a third party to secure their assets and transactions.

Decentralization - A blockchain provides a platform that reduces the requirement of a centralised intermediary to ensure security of one's assets. Because of the distributed and decentralised structure of the blockchain, a hacker or a government cannot access the centralised ledger for individual gain.

Users' anonymity - The Blockchain allows for transactions between addresses. Every operator on a Blockchain has their own address which includes numbers \& alphabets, which they can hold secret or share. People can interact with the Blockchain network using the generated address, and individuals' private data is no longer kept by a central entity. Part of the person's privacy is protected by this way. Blockchain, however, is unable to give total privacy protection due to its constraints.

Consensus mechanism - A consensus method is used since there is no single trusted entity in the existing system. The group's purpose is to come to an agreement on how the whole record should be authenticated. By controlling more than $51 \%$ of the financial nodes in the total infrastructure, it is feasible to create a record which is not present. As a result, any damage is immediately apparent.

Execution - Interactions across nodes can be induced using rules and algorithms. Blockchain could also run programmes if specific conditions are met. The combination of Blockchain properties like decentralisation, anonymity, and immutability makes this new technology lucrative.

Figure 6: Characteristics of Blockchain technology

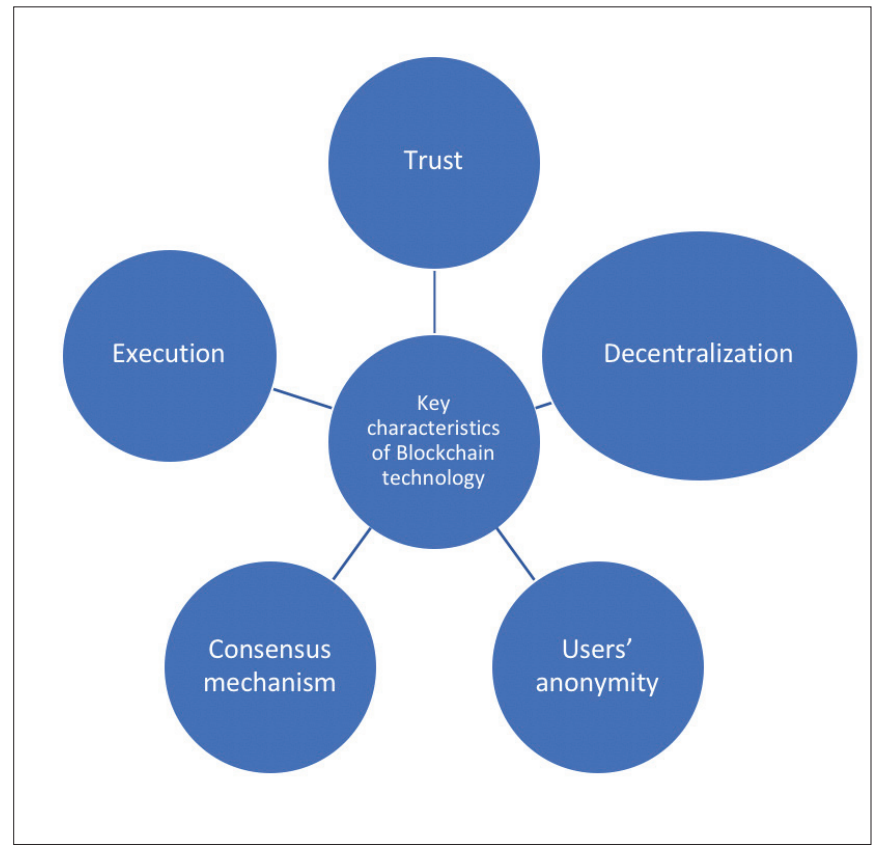

Source: Authors' compilation

On the basis of above characteristics, it can be concluded that Blockchain removes the requirement of middle man or third-party, eliminates the threat from hackers, protects users privacy and information, easily detects distortion and its ease of execution attracts users. Thus, the characteristics of blockchain technology can be termed as secure and easy for users.

Next section explains the adoption of blockchain technology and challenges faced by industries.

\section{Adoption and challenges in blockchain technology}

Blockchain technology adoption. A blockchain is a decentralised, diffused, and unchangeable collection of data of account (Yoo, 2017). The greatest valuable aspect of Blockchain is that it is a decentralised structure with a long security chain. A blockchain is a collection of bitcoin chunks connected by chains. This novel concept has sparked a lot of curiosity in the FinTech world (Mu, 2016). Every block comprises transaction information, hash of earlier block and timestamp, all of which are bound by cryptography. Satoshi Nakamoto created the first Blockchain in 2008, Adding blocks to a network without the use of a trustworthy 3rd party via a Hash cash-like mechanism (Narayanan et al., 2016).

Because of the rise of bitcoin, blockchain has gained popularity. However, this technology isn't just for the financial industry. Maintaining individual credit records, Medical data, tracing the movements of products, monitoring the artwork origin, payment confirmation 
in a supply chain, binding agreements and blockchains could be used for a lot more. (Milic, 2019). According to recent research, the market for blockchain technology would be worth $\$ 8$ billion by 2025 which is a growth rate of around 37.4 percent. Increased popularity of blockchain among all sectors including public services, healthcare, transportation, communication and media, industrial and consumer goods and financial services (Grand View Research, 2019).

Figure 7: Adoption of Blockchain technology
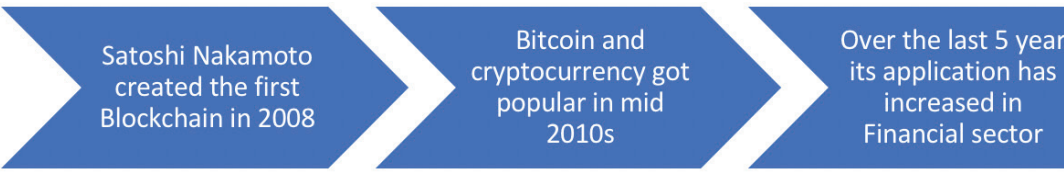

Presently, there is

increased demand

for this technology

across all industries

Source: Authors' compilation

The main benefit of Blockchain is the distributed trust it provides: (1) it reduces the requirement for a trustworthy third party to enable payments, and (2) it reduces transaction costs, (3) shortening the duration (Staples et al., 2017). As a result, commercial and industrial revolutions are expected to be sparked by blockchain while also promoting global economic change (Underwood, 2016). Thus, Blockchain is a rapidly developing financial technology and is changing the way people do business (Antonio and DiNizo, 2018).

The next section explains the blockchain's challenges in its application.

The blockchain's challenges. The challenges faced in applying blockchain in the financial sector are latency, privacy, security and scalability (Chang et al. 2020). The financial sector is still looking for solutions to these issues. Additionally, Zachariadis, Hileman and Scott (2019) in their study also explained the challenges such as privacy, security and scalability similar to the study of Chang et al. 2020 But they mentioned a few more challenges such as Interoperability and standards, resilience and liability, and transparency.

Furthermore, the challenges faced by the banking sector in application of blockchain technology are identified as requirements of standardization and cost, stability of currency, high security, regulations and legislations, and scalability (Hassani, Huang and Silva, 2018). On the other hand, Lewis, McPartland, and Ranjan (2017) in their paper explained the challenges faced by blockchain technology in two categories such as regulatory and technical \& business challenges. The paper described the technical and business challenges such as immutability, efficiency, scalability, interoperability, standardization, intellectual property, legal uncertainty, privacy, liquidity, security and achieving consensus. The paper also explains the regulatory challenges such as control on currency and uncertainty.

Also, the challenges of using blockchain technology in banking are reluctance to change, Bitcoin not as the most popular and acceptable currency, lack of legal acceptance in the insurance sector, and the framework of bitcoin is not as transparent as the policy maker claims (Nguyen, 2016). Additionally, Hileman \& Rauchs (2017) in their study explained the challenges such as obstacles of DLT adoption, scalability and performance, data protection laws, and confidentiality and privacy.
Figure 8: Challenges of Blockchain technology

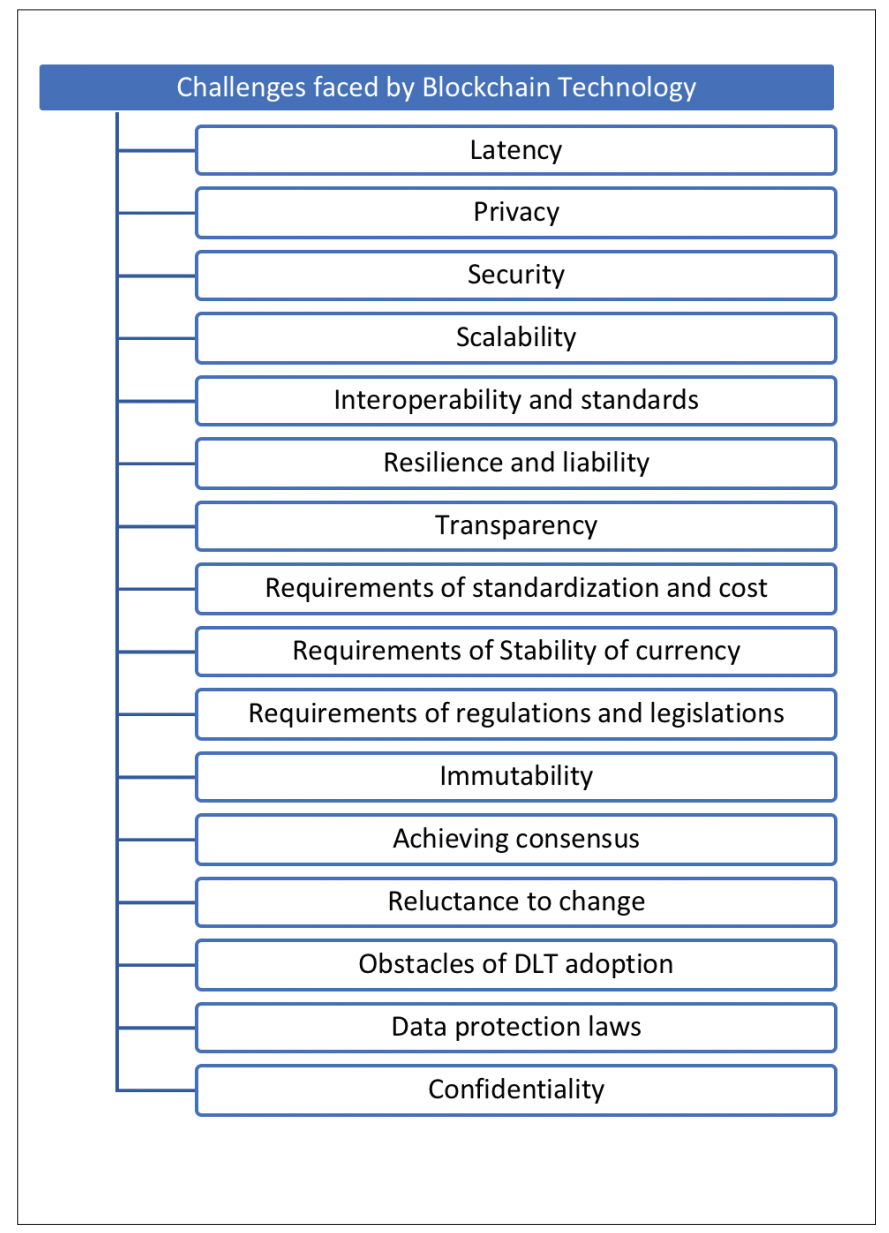

Source: Authors' compilation

On the basis of the above papers, it is found that most researchers have explained blockchain's challenges in common such as scalability, security and privacy. Thus, there is still scope for improvement in blockchain technology to make it a more secure application.

The next section explains the objective of current research i.e. usage of blockchain in e-finance and financial sector. 


\section{Application of blockchain in financial sector \& e-finance}

Figure 9: Utility of Blockchain technology

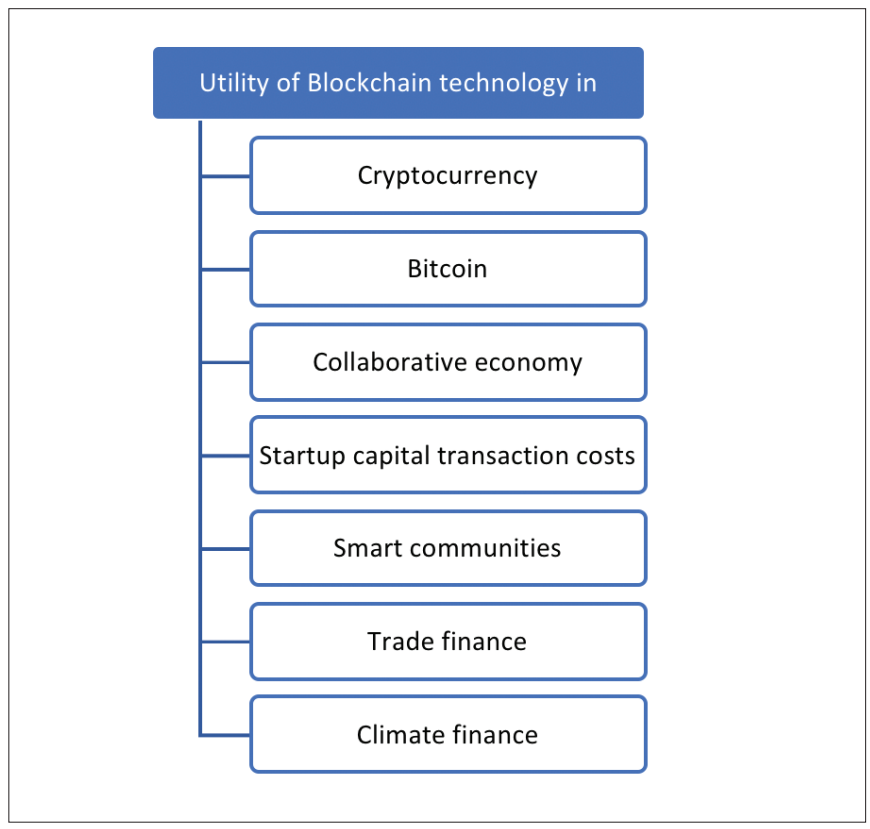

Source: Authors' compilation

Effect of Blockchain on financial serviceS. This section describes the studies explaining the influence of Blockchain technology on sector of finance. Most of the papers focus on usage of blockchain in the banking sector and very few suggest its use in the insurance industry.

Benefits of blockchain technology are numerous in banking sector such as increased transparency, increased speed of transaction, increased traceability, reduced cost, the ability to keep track of safe payment history, and reduced threat of fraud (Ali et al.2020). Additionally, various Indian banks including SBI are viewing the use of blockchain to advance customer experience (Garg et al. 2020). The paper also describes the use of blockchain technology in maintaining back-end utilities, fund transfer and registration. Similar to Ali et al study, this paper also explains that blockchain technology will bring transparency, traceability, reduced fraud and reduced cost in banking operations.

Moreover, the use of blockchain in functions and operations of banking sector will eliminate the requirement of KYC, speed up transactions, reduce cost, increase security for both customers \& banks and introduce smart contracts (Hassani, Huang \& Silva, 2018). The study also discusses the problems that the banking industry has faced in adopting blockchain in banks.
All these papers are concentrating on the characteristics of blockchain such as secure, fast, transparent, reduced cost, reduced threat of fraud, and improved efficiency of the banking system.

Furthermore, the usage of cryptocurrencies and the advantages of blockchain in banks can be explained as increased transparency, reduced cost, faster payments especially in export sales (Kimani et al. 2020). The article also discusses how blockchain technology is used in capital markets, such as the payment ledger for notes and bonds and stock issuances. Additionally, Fannings \& Centers (2016) in their article explained that blockchain technology was first introduced in the financial sector in handling back-office work. The article also describes that NASDAQ in association with Chain is applying blockchain technology in transferring and issuing shares.

These two papers described the usage of blockchain in banks and the capital market. These papers also focus on the secure, transparent and fast characteristic of blockchain technology which led its use in the financial sector.

Furthermore, the usage of blockchain in the insurance industry can be explained as the use of blockchain in smart contracts in insurance, to prevent fraud claims, streamlining payments, eliminates the requirement of intermediaries such as agents and brokers, and in optimizing the functional area of insurance business (Kar \& Navin, 2021).

Additionally, the possible usage of blockchain technology in financial services such as digital assets (Digital assets might effectively act as online financial assets that trade hands whenever the owner of an asset recorded in a ledger changes), digital currencies (in the era of internet banking, e-payments, and e-transactions, in which real currencies are rarely used, various types of cryptocurrencies have been used for real-world transactions in recent years), Digital record keeping and smart contracts (Lewis, McPartland, and Ranjan, 2017).

Also, usage of blockchain technology in financial activities such as banks can better understand important financial movements thanks to successful testing on recordkeeping technology behind Bitcoin about credit default swaps (Nguyen, 2016). Blockchain also helps to separate the operations of transferring money and saving, making it more convenient for small businesses to receive and send money, as well as convert to US dollars. It enables managers to conduct financial transactions deprived of the necessity of a middleman. 
Figure 10: Influence of Blockchain technology in finance

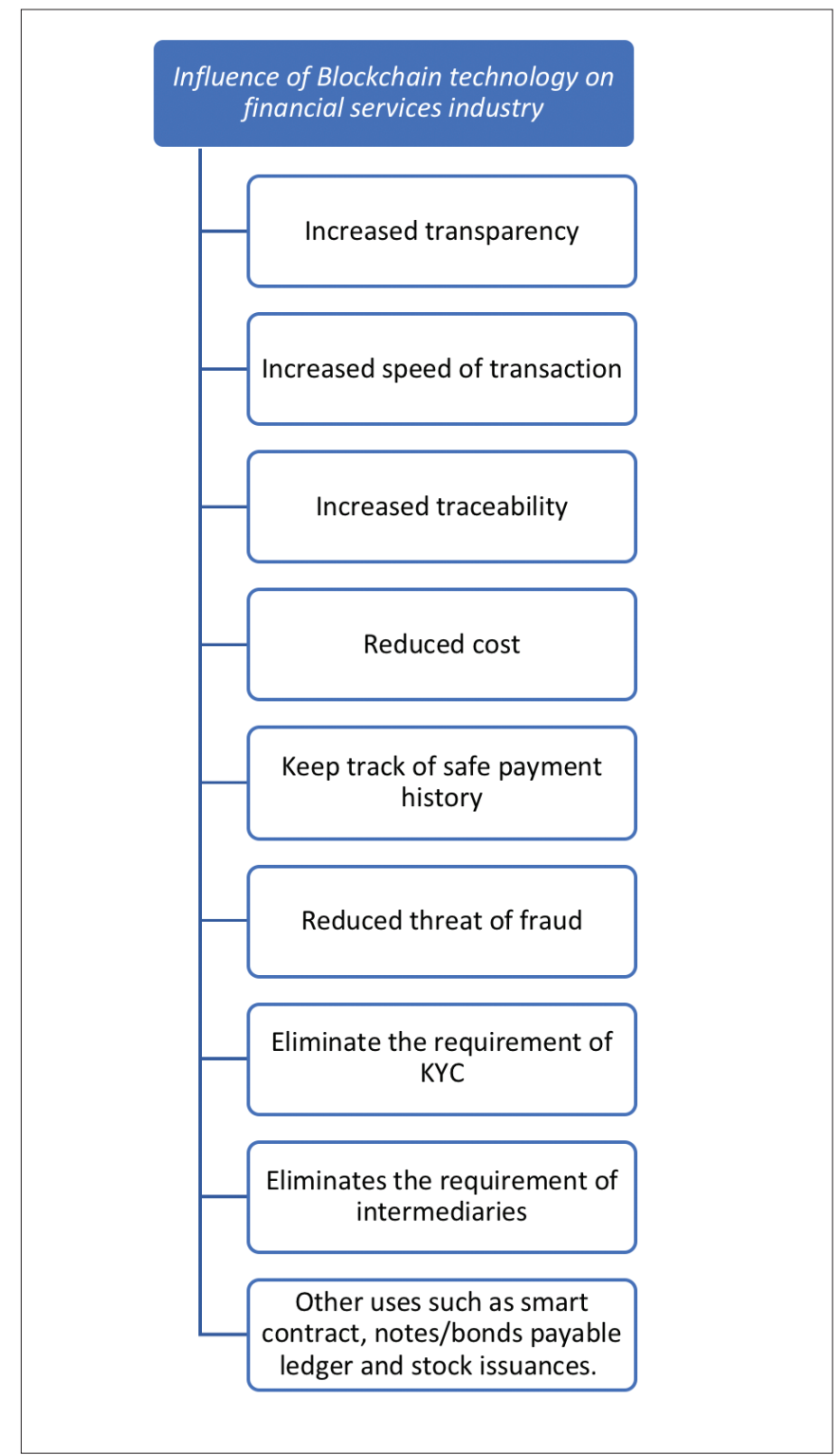

Source: Authors' compilation

Thus, all these papers show that blockchain technology can bring revolutionary changes in the financial sector by eliminating the need for foreign exchange, intermediaries, increasing the efficiency of operations and functional activities of financial services.

Using of Blockchain in e-finance. The usability of blockchain by looking at the behavioural factors that influence customers' willingness to engage in blockchain-based cryptocurrency transactions (Albayati, Kim and Rho, 2020). Given the technology's complexity, this research offers a new model: The Technology Acceptance Model (TAM) is used in combination with new exterior variables to determine the features of blockchain adoption. On the other hand, Solà and Bariviera (2019) in their paper explained current trends and state of research related to bitcoin in several scientific areas using bibliometric analysis. Also, Klarin (2020) in his paper conducted a systematic review of literature and covered themes including bitcoin, cryptocurrency and blockchain. The paper provides guidance to practitioners and academicians related to the above theme mentioned.

\section{BITCOIN}

The Bitcoin blockchain may be used to produce a revolutionary choreography solution. Despite the fact that the Bitcoin blockchain was designed with a definite practice case in mind, its initial design allows for a wide range of experimental transactions (Prybila et al. 2017). Thus, Prybila et al. (2017) in their study explored various possibilities by applying a process runtime verification approach. On the other hand, Akcora et al. (2018) in their study investigated the types of chainlets that suggest risk of loss, as well as a possible effect on Bitcoin's volatility and price. According to study, the revolutionary data representation allows for a completely new type of financial econometrics, focusing on topological network structures rather than the covariance of historical price series.

Moreover, the current fiscal and regulatory policy methods to digital currency in order to lay the groundwork for additional policy \& legal measures is aimed at reducing Blockchain's consumption of energy (Truby, 2018). Digital currencies, the most well-known of which is Bitcoin, are examples of financial technology which has been one of many usage of Blockchain and the speculative drive of individual wealth accumulation with little societal use has essentially replaced this secure and decentralised peer-to-peer payments system. The situation is simply going to become worse as higher Bitcoin's value rises, new digital currencies based on similar carbonised notions will arise as motivation to mine grows.

Furthermore, Blockchain was created with the intention of serving as the Bitcoin distributed ledger. New blockchains that employ the Bitcoin source code have arisen as a result of the rising interest in Bitcoin (Islam, Mäntymäki and Turunen, 2019). In order to create new blockchains, Bitcoin developers have modified and enhanced the original Bitcoin technology. In this sense, the creation of a new Altcoin could be viewed as a schism in the community.

Additionally, the Bitcoin network's local topology and geometry during its first decade of existence has changed over a period of time (Nerurkar et al. 2020). The numerous structural aspects of the Bitcoin system are- it is in network equality, community structure with timeevolving, degree assortativity, densification power law, network diameter and the longest linked component.

The above studies show that one of the initial uses of blockchain technology in finance was Bitcoin as currency. There are various studies conducted showing the opportunities and challenges related to this technology in the finance sector. Next section describes the use of blockchain technology in cryptocurrency.

\section{CRYPTOCURRENCY}

There are four important roles played by individuals in shaping cryptocurrency markets and bitcoin market (Breidbach and Tana, 2021). 
These are referred to as "Fortune Hunter',' Trail-Blazer, "Freshman" and "Idealist". The study defines general public as freshman, those who have little knowledge of cryptocurrency and have invested also were termed as fortune hunter while those how invest in cryptocurrency not for capital gain but for knowledge gain were termed as idealist and last, individuals with expert knowledge and finding solutions related to challenges faced by cryptocurrency as termed as Trail-Blazer.

Furthermore, cryptocurrencies have regulatory uncertainty and bubble-like instabilities, whereas blockchain technologies are gaining traction in operationalization and business model innovation (Klarin, 2020). Additionally, the characteristics of the cryptocurrency market's exchange rate complexity have begun to resemble those of traditional and mature markets such as currencies, bonds, commodities and equity (Watorek et al. 2020). The study explains that despite its current high volatility, the cryptocurrency market provides new investment alternatives, allowing for portfolio diversification.

Furthermore, the bitcoin market considers regulatory events to be value-destroying, with the potential for wider adoption and risk reduction valued higher than the efficiency and consumer value losses associated with regulation implementation (Shanaev et al. 2020)).

Many cryptocurrencies were established but the most well-known and successful was Bitcoin, which was built utilising blockchain technology (Ghosh et al. (2020). The core technology used to construct other cryptocurrencies was also blockchain technology as it has features such as secure, no requirement of third party and decentralized.

All these papers contribute to the explanation of the usage of blockchain in developing cryptocurrency among which bitcoin is the most popular cryptocurrency. The studies further show that these digital currencies will bring revolution in capital market and trading.

\section{Summary}

The purpose of this study was to conceptualise financial implications of blockchain, with an emphasis on how it is revolutionising banking, insurance, and capital markets. The paper outlines some of the primary benefits of blockchain technology in relationships to how financial institutions might use it to reduce operational, agency, and transaction costs. Blockchain's unique technical abilities have the potential to transform the financial sector while also enhancing its transparency and trust in cyberspaces. When combines with technologies of field-sensing suchas IoT and AI, blockchain has the possible to significantly improve insurance, banking, capital markets and international trade.

The systematic literature review reveals that few studies have criticised the technology, claiming that it is unregulated. The blockchain which is oriented to finding solutions appears to occur within the limits of anarcho-capitalists who use it as a source of political and financial power with little regard for democratic, political, and legal transparency.

\section{Conclusion}

Blockchain has been rapidly gaining traction in the worldwide market recently, offering a number of options for securing transactions and services. This research reveals that the majority of the literature on financial services and e-finance are focused on cryptocurrencies majorly in the stream of economics and computer science. Thus, the most common blockchain applications are cryptocurrencies, despite the fact that it was created as a technology product. Bitcoin is the most popular of them, both in the market and in literature.

According to this analysis, the financial industry is on the approach of a new financial age, one marked by a new disruptive structure based on Blockchain. The prior financial industry products and services were thought to be inefficient and pricey. As a result, a significant shift was required. Although more work remains to be done to fix the underlying challenges, blockchain technology has the potential to advance the efficiency and security of financial markets.

There is a requirement to upgrade system and technology oversight to the Blockchain while the development of Blockchain is still in its early stages. The government and related departments should develop laws to allow the general people to profit from Blockchain while severely prohibiting the use of Blockchain for criminal purposes such as capital control, financing terrorist and money laundering. Without a doubt, Blockchain is a cutting-edge and "imaginative" technology with the potential to change the commercial and financial architecture of our civilization in the future.

Financial services should take a perspective which is long-term and begin studying how Blockchain might help them improve their business, or they risk being left behind due to competition. Blockchain has the potential to permit peer-to-peer transactions, widen transaction possibility, lesser transaction costs and piloting in a new era of decentralised business models. As a result of this new paradigm, decentralised finance has evolved, which employs blockchain technology to create an alternative financial system that is more borderless, interoperable, innovative, transparent, and decentralised.

\section{Future scope of study}

The present research suggests future scope of study such as lack of knowledge among people for blockchain technology and its applications, not just financial services. Furthermore, research can be conducted to develop a framework that can assist and allow for more structured and balanced knowledge sharing or financial transactions.

Additionally, A future study can be conducted concentrating on the technical, organisational, and people (TOP) variables that affect effective Blockchain adoption and the ability of Blockchain to adequately serve various types of corporate operations and services.

Also, future researchers can look at the adoption of developing technologies such as cognitive computing, blockchain and artificial 
intelligence in certain sectors or services. Future research could try to better understand why various qualities of blockchain have been discovered, as well as the factors that influence their diffusion.

Furthermore, there is virtually little research on supply chain financing in general. There is no solid research on the interaction between supply chain financing and blockchain technology in particular. As a result, the integration of blockchain technology into supply chain systems offers rich ground for future research. Thus, a future study can be conducted on supply chain financing.

Also, research can be conducted to examine how technology leaders will deal with the volatility and unpredictability of blockchain.

\section{References}

Abou Jaoude, J., \& Saade, R. G. (2019). Blockchain applications-usage in different domains. IEEE Access, 7, 45360-45381.

Akcora, C. G., Dixon, M. F., Gel, Y. R., \& Kantarcioglu, M. (2018). Bitcoin risk modeling with blockchain graphs. Economics Letters, 173, 138-142.

Albayati, H., Kim, S. K., \& Rho, J. J. (2020). Accepting financial transactions using blockchain technology and cryptocurrency: A customer perspective approach. Technology in Society, 62, 101320.

Ali, O., Ally, M., \& Dwivedi, Y. (2020). The state of play of blockchain technology in the financial services sector: A systematic literature review. International Journal of Information Management, 54, 102199.

Allen, F., McAndrews, J., \& Strahan, P. (2002). E-finance: an introduction. Journal of financial services research, 22(1), 5-27.

Andolfatto, D. (2018). Blockchain: What it is, what it does, and why you probably don't need one. Federal Reserve Bank of St. Louis Review, 100(2), 87-95.

Anoop Bhola, N. (2021). "BLOCKCHAIN BASED PRIVACY PRESERVATION IN HEALTHCARE: A RECENT TRENDS AND CHALLENGES". Psychology And Education Journal, 58(1), 5315-5324. doi: 10.17762/pae.v58i1.2122

Ante, L. (2020). Smart contracts on the blockchain-a bibliometric analysis and review. Telematics and Informatics, 101519.

Ante, L., \& Fiedler, I. (2021). Market reaction to large transfers on the Bitcoin blockchain-Do size and motive matter?. Finance Research Letters, 39, 101619.

Asongu, S., \& Nnanna, J. (2018). ICT in reducing information asymmetry for financial sector competition. DBN Journal of Economics and Sustainable Growth (Forthcoming), AGDI Working Paper No. WP/18/035.

Bai, S., Yang, G., Rong, C., Liu, G., \& Dai, H. (2020). QHSE: An efficient privacy-preserving scheme for blockchain-based transactions. Future Generation Computer Systems, 112, 930-944.
Böhme, R., Christin, N., Edelman, B., \& Moore, T. (2015). Bitcoin: Economics, technology, and governance. Journal of economic Perspectives, 29(2), 213-38.

Breidbach, C. F., \& Tana, S. (2021). Betting on Bitcoin: How social collectives shape cryptocurrency markets. Journal of Business Research, $122,311-320$

Brereton, P., Kitchenham, B. A., Budgen, D., Turner, M., \& Khalil, M. (2007). Lessons from applying the systematic literature review process within the software engineering domain. Journal of systems and software, 80(4), 571-583.

Chang, V., Baudier, P., Zhang, H., Xu, Q., Zhang, J., \& Arami, M. (2020). How Blockchain can impact financial services-The overview, challenges and recommendations from expert interviewees. Technological forecasting and social change, 158, 120166.

Chen, Y., \& Bellavitis, C. (2020). Blockchain disruption and decentralized finance: The rise of decentralized business models. Journal of Business Venturing Insights, 13, e00151.

Cioroianu, I., Corbet, S., \& Larkin, C. (2021). The differential impact of corporate blockchain-development as conditioned by sentiment and financial desperation. Journal of Corporate Finance, 66, 101814.

Claessens, S., Klingebiel, D., \& Glaessner, T. (2002). E-Finance: A New Approach to Financial Sector Development? Financial Markets, Institutions and Instruments, 11.

Conti, M., Gangwal, A., \& Ruj, S. (2018). On the economic significance of ransomware campaigns: A Bitcoin transactions perspective. Computers \& Security, 79, 162-189.

Corbet, S., Larkin, C., Lucey, B., Meegan, A., \& Yarovaya, L. (2020). Cryptocurrency reaction to fomc announcements: Evidence of heterogeneity based on blockchain stack position. Journal of Financial Stability, 46, 100706.

Cronin, P., Ryan, F., \& Coughlan, M. (2008). Undertaking a literature review: a step-by-step approach. British journal of nursing, 17(1), 38-43.

Ertz, M., \& Boily, É. (2019). The rise of the digital economy: Thoughts on blockchain technology and cryptocurrencies for the collaborative economy. International Journal of Innovation Studies, 3(4), 84-93.

Fanning, K., \& Centers, D. P. (2016). Blockchain and its coming impact on financial services. Journal of Corporate Accounting \& Finance, 27(5), 53-57.

Frizzo-Barker, J., Chow-White, P. A., Adams, P. R., Mentanko, J., Ha, D., \& Green, S. (2020). Blockchain as a disruptive technology for business: A systematic review. International Journal of Information Management, 51, 102029.

Gao, F., Zhu, L., Shen, M., Sharif, K., Wan, Z., \& Ren, K. (2018). A blockchain-based privacy-preserving payment mechanism for vehicle-to-grid networks. IEEE network, 32(6), 184-192. 
Garg, P., Gupta, B., Chauhan, A. K., Sivarajah, U., Gupta, S., \& Modgil, S. (2021). Measuring the perceived benefits of implementing blockchain technology in the banking sector. Technological Forecasting and Social Change, 163, 120407.

Ghosh, A., Gupta, S., Dua, A., \& Kumar, N. (2020). Security of Cryptocurrencies in blockchain technology: State-of-art, challenges and future prospects. Journal of Network and Computer Applications, 163, 102635.

Hadidi, R. (2003). The Status of E-finance in Developing Countries. The Electronic Journal of Information Systems in Developing Countries, 11(1), 1-5.

Harwick, C., \& Caton, J. (2020). What's holding back blockchain finance? On the possibility of decentralized autonomous finance. The Quarterly Review of Economics and Finance. 10.1016/j. qref.2020.09.006.

Hassani, H., Huang, X., \& Silva, E. (2018). Banking with blockchained big data. Journal of Management Analytics, 5(4), 256-275.

Hek, G., \& Langton, H. (2000). Systematically searching and reviewing literature. Nurse Researcher (through 2013), 7(3), 40.

Hendrikse, R., Van Meeteren, M., \& Bassens, D. (2020). Strategic coupling between finance, technology and the state: Cultivating a Fintech ecosystem for incumbent finance. Environment and Planning A: Economy and Space, 52(8), 1516-1538.

Howson, P., Oakes, S., Baynham-Herd, Z., \& Swords, J. (2019). Cryptocarbon: the promises and pitfalls of forest protection on a blockchain. Geoforum, 100, 1-9.

Hu, Y., Hou, Y. G., Oxley, L., \& Corbet, S. (2021). Does blockchain patent-development influence Bitcoin risk? Journal of International Financial Markets, Institutions and Money, 70, 101263.

Hughes, A., Park, A., Kietzmann, J., \& Archer-Brown, C. (2019). Beyond Bitcoin: What blockchain and distributed ledger technologies mean for firms. Business Horizons, 62(3), 273-281.

Islam, A. N., Mäntymäki, M., \& Turunen, M. (2019). Why do blockchains split? An actor-network perspective on Bitcoin splits. Technological Forecasting and Social Change, 148, 119743.

Janssen, M., Weerakkody, V., Ismagilova, E., Sivarajah, U., \& Irani, Z. (2020). A framework for analysing blockchain technology adoption: Integrating institutional, market and technical factors. International Journal of Information Management, 50, 302-309.

Kar, A. K., \& Navin, L. (2020). Diffusion of blockchain in insurance industry: An analysis through the review of academic and trade literature. Telematics and Informatics, 101532.

Kastner, M., Tricco, A. C., Soobiah, C., Lillie, E., Perrier, L., Horsley, T., ... \& Straus, S. E. (2012). What is the most appropriate knowledge synthesis method to conduct a review? Protocol for a scoping review. BMC Medical Research Methodology, 12(1), 1-10.
Kimani, D., Adams, K., Attah-Boakye, R., Ullah, S., Frecknall-Hughes, J., \& Kim, J. (2020). Blockchain, business and the fourth industrial revolution: Whence, whither, wherefore and how?. Technological Forecasting and Social Change, 161, 120254.

Kitchenham, B., Pearl Brereton, O., Budgen, D., Turner, M., Bailey, J., \& Linkman, S. (2009). Systematic literature reviews in software engineering - A systematic literature review. Information And Software Technology, 51(1), 7-15.

Klarin, A. (2020). The decade-long cryptocurrencies and the blockchain rollercoaster: Mapping the intellectual structure and charting future directions. Research in International Business and Finance, 51, 101067.

Kong, S. T., \& Loubere, N. (2021). Digitally Down to the Countryside: Fintech and Rural Development in China. The Journal of Development Studies, 1-16.

Lee, J. Y. (2019). A decentralized token economy: How blockchain and cryptocurrency can revolutionize business. Business Horizons, 62(6), 773-784.

Levy, Y., \& Ellis, T. J. (2006). A systems approach to conduct an effective literature review in support of information systems research. Informing Science, 9.

Lewis, R., McPartland, J., \& Ranjan, R. (2017). Blockchain and financial market innovation. Economic Perspectives, 41(7), 1-17.

Lin, C., Ma, N., Wang, X., \& Chen, J. (2020). Rapido: Scaling blockchain with multi-path payment channels. Neurocomputing, 406, 322-332.

Liu, Z., \& Li, Z. (2020). A blockchain-based framework of cross-border e-commerce supply chain. International Journal of Information Management, 52, 102059.

Lycklama à Nijeholt, H., Oudejans, J., \& Erkin, Z. (2017, April). DecReg: A framework for preventing double-financing using blockchain technology. In Proceedings of the ACM Workshop on Blockchain, Cryptocurrencies and Contracts (pp. 29-34).

Ma, Y., Ahmad, F., Liu, M., \& Wang, Z. (2020). Portfolio optimization in the era of digital financialization using cryptocurrencies. Technological forecasting and social change, 161, 120265.

Mays, N., Pope, C., \& Popay, J. (2005). Systematically reviewing qualitative and quantitative evidence to inform management and policymaking in the health field. Journal of health services research \& policy, 10(1_suppl), 6-20.

McLean, S., \& Deane-Johns, S. (2016). Demystifying Blockchain and Distributed Ledger Technology - Hype or Hero?. Computer Law Review International, 17(4).

Meegan, A., Corbet, S., Larkin, C., \& Lucey, B. (2021). Does cryptocurrency pricing response to regulatory intervention depend on underlying blockchain architecture?. Journal of International Financial Markets, Institutions and Money, 70, 101280. 
Merediz-Solà, I., \& Bariviera, A. F. (2019). A bibliometric analysis of bitcoin scientific production. Research in International Business and Finance, 50, 294-305.

Naughton, J. (2016). Is Blockchain the most important IT invention of our age. The Guardian, 24.

Nawari, N. O., \& Ravindran, S. (2019). Blockchain and the built environment: Potentials and limitations. Journal of Building Engineering, 25, 100832.

Nerurkar, P., Patel, D., Busnel, Y., Ludinard, R., Kumari, S., \& Khan, M. K. (2021). Dissecting bitcoin blockchain: Empirical analysis of bitcoin network (2009-2020). Journal of Network and Computer Applications, 177, 102940.

Nguyen, Q. K. (2016, November). Blockchain-a financial technology for future sustainable development. In 2016 3rd International conference on green technology and sustainable development (GTSD) (pp. 51-54). IEEE.

Novo, O. (2018). Blockchain meets IoT: An architecture for scalable access management in IoT. IEEE Internet of Things Journal, 5(2), 1184-1195.

Nguyen, Q. K. (2016, November). Blockchain-a financial technology for future sustainable development. In 2016 3rd International conference on green technology and sustainable development (GTSD) (pp. 51-54). IEEE.

Ozbayoglu, A. M., Gudelek, M. U., \& Sezer, O. B. (2020). Deep learning for financial applications: A survey. Applied Soft Computing, 93, 106384.

Papadopoulos, G. (2015). Blockchain and digital payments: an institutionalist analysis of Cryptocurrencies. In Handbook of digital currency (pp. 153-172). Academic Press.

Parahoo, K. (2006). Nursing research Principles, processes and issues 2nd edition Palgrave Macmillan Basingstoke.

Pass, R., \& Shelat, A. (2015, October). Micropayments for decentralized currencies. In Proceedings of the 22nd ACM SIGSAC Conference on Computer and Communications Security (pp. 207-218).

Poongodi, M., Sharma, A., Vijayakumar, V., Bhardwaj, V., Sharma, A. P., Iqbal, R., \& Kumar, R. (2020). Prediction of the price of Ethereum blockchain cryptocurrency in an industrial finance system. Computers \& Electrical Engineering, 81, 106527.

Prybila, C., Schulte, S., Hochreiner, C., \& Weber, I. (2020). Runtime verification for business processes utilizing the Bitcoin blockchain. Future Generation Computer Systems, 107, 816-831.

Poongodi, M., Sharma, A., Vijayakumar, V., Bhardwaj, V., Sharma, A. P., Iqbal, R., \& Kumar, R. (2020). Prediction of the price of Ethereum blockchain cryptocurrency in an industrial finance system. Computers \& Electrical Engineering, 81, 106527.

Rashideh, W. (2020). Blockchain technology framework: Current and future perspectives for the tourism industry. Tourism Management, 80, 104125.
Reyna, A., Martín, C., Chen, J., Soler, E., \& Díaz, M. (2018). On blockchain and its integration with IoT. Challenges and opportunities. Future generation computer systems, 88, 173-190.

Saito, K., \& Yamada, H. (2016, June). What's so different about blockchain?-blockchain is a probabilistic state machine. In 2016 IEEE 36th International Conference on Distributed Computing Systems Workshops (ICDCSW) (pp. 168-175). IEEE.

Salimitari, M., Chatterjee, M., \& Fallah, Y. P. (2020). A survey on consensus methods in blockchain for resource-constrained IoT networks. Internet of Things, 11, 100212.

Shahrokhi, M. (2008). E-finance: status, innovations, resources and future challenges. Managerial Finance, 34(6), 365-398

Shanaev, S., Sharma, S., Ghimire, B., \& Shuraeva, A. (2020). Taming the blockchain beast? Regulatory implications for the cryptocurrency Market. Research in International Business and Finance, 51, 101080.

Silva, M., \& Junior, M. (2016). A Secure Protocol for Exchanging Cards in P2P Trading Card Games Based on Transferable e-cash. Journal Of Information Security And Cryptography (Enigma), 3(1), 26. doi: 10.17648/enig.v3i1.57

Taylor, P. J., Dargahi, T., Dehghantanha, A., Parizi, R. M., \& Choo, K. K. R. (2020). A systematic literature review of blockchain cyber security. Digital Communications and Networks, 6(2), 147-156.

Treat, D., Brodersen, C., Blain, C., \& Kurbanov, R. (2017). Banking on Blockchain-A Value Analysis for Investment Banks. Accent. Consult, 10.

Treiblmaier, H., \& Sillaber, C. (2021). The impact of blockchain on e-commerce: a framework for salient research topics. Electronic Commerce Research and Applications, 48, 101054.

Truby, J. (2018). Decarbonizing Bitcoin: Law and policy choices for reducing the energy consumption of Blockchain technologies and digital currencies. Energy research \& social science, 44, 399-410.

Treat Vranken, H. (2017). Sustainability of bitcoin and blockchains. Current opinion in environmental sustainability, 28, 1-9.

Walch, A. (2015). The bitcoin blockchain as financial market infrastructure: A consideration of operational risk. NYUJ Legis. \& Pub. Poly, 18, 837.

Wątorek, M., Drożdż, S., Kwapień, J., Minati, L., Oświęcimka, P., \& Stanuszek, M. (2021). Multiscale characteristics of the emerging global cryptocurrency market. Physics Reports, 901, 1-8

Yli-Huumo, J., Ko, D., Choi, S., Park, S., \& Smolander, K. (2016). Where is current research on blockchain technology? - a systematic review. PloS one, 11(10), e0163477.

Zhong, L., Wu, Q., Xie, J., Guan, Z., \& Qin, B. (2019). A secure largescale instant payment system based on blockchain. Computers \& Security, 84, 349-364. 
